\title{
A Morphofunctional Hypothesis for Selection on EDAR V370A and Associated Elements of Sinodonty
}

\author{
Robert Dudley ${ }^{1,2 *}$ \\ 1 University of California, Berkeley \\ 2 Smithsonian Tropical Research Institute
}

Keywords: agriculture, China, diet, EDAR V370A, shoveling

\begin{abstract}
The phenomenon of Sinodonty refers to a suite of dental characters shared between East Asian and Native American populations, and most prominently to the presence of shoveled incisors. Although this syndrome is a conspicuous aspect of dental differentiation among extant human populations, elements of which have been recent subject of detailed genetic analysis, adaptive consequences of shoveled incisors and related features remain unclear. Here, I hypothesize that many of the associated differences in dentition (along with reduction in mandibular length and increases in salivary gland branching) arose in parallel with the opportunistic consumption of wild rice and millet in central and northern China, respectively, and with their subsequent domestication in the Upper Paleolithic. More efficient mastication and digestion of plant grains (and of other starchy foods obtained via broadspectrum foraging) would potentially have been enabled by these traits, yielding greater rates of nutritional intake as wild crops were progressively domesticated. This functional hypothesis, although not mutually exclusive relative to other proposed selective factors, matches the estimated timeline in China for both origin and time to fixation of the associated allele (EDAR V370A), and is consistent with chronic energetic gain and fitness benefits independent of any assumptions for concurrent climatic conditions.
\end{abstract}

Lingually shoveled incisors, an anatomical feature first described by Hrdlička $(1920,1921)$, are a salient characteristic of the phenomenon now termed Sinodonty, a suite of dental characters common between Native American and East Asian populations, but occurring at much lower frequencies in non-Sinodont populations (Turner, 1971, 1976, 1986, 1990; see also Mizoguchi, 1985; Scott \& Turner, 1988; Stojanowski et al., 2013; Scott et al., 2018). This disjunct geographical distribution has historically provided strong indirect support for hypothesized Old World origins of New World human populations (e.g., Turner \& Bird, 1981). Anatomically, the condition of Sinodonty refers primarily to the presence of posteriorly shoveled incisors, single-rooted upper premolars, and threerooted lower molars, and is strongly heritable (Hanihara et al., 1974; Blanco and Chakraborty, 1976), but is also likely to be polygenic in origin. Genetically, presence of the allele EDAR V370A significantly influences the condition of incisor shoveling along with a variety of other ectodermic features, including increased thickness of scalp hairs (see Bryk et al., 2008; Fujimoto et al., 2008; Chang et al., 2009; Kimura et al., 2009). Increased tooth crown size also associates with EDAR V370 (Kimura et al., 2009; Park et al., 2012), and its greater expression in mice furthermore reduces mandibular length (Adhikari et al., 2016). Pleiotropic effects of this allele are thus substantial.

Positive selection on EDAR V370A has been intense in humans, consistent with its very high frequencies in East Asian and Native American populations relative to other groups (see Sabeti et al., 2007; Bryk et al., 2008; Kamberov et al., 2013; Hlusko et al., 2018). Demic modelling based on extant frequencies of EDAR V370A in primarily Asian populations (Kamberov et al., 2013) indicates geographical origins of the allele in central and north China, within a region broadly congruent with the extensive alluvial plains of the Yellow, Huai, and

\footnotetext{
${ }^{*}$ Correspondence to:

Robert Dudley

Department of Integrative Biology

University of California, Berkeley;

Smithsonian Tropical Research Institute

Balboa, Republic of Panama

wings@berkeley.edu
} 
Yangtzi (Changjiang) Rivers. This demic model also places time of origination for the allele between $\sim 40,000$ and $\sim 13,000$ years BP, with a modal value of 35,300 years BP. A parallel approach to allele age using maximum likelihood estimation for data from modern Han Chinese places origination between $\sim 38,000$ and $\sim 35,000$ years BP (see Kamberov et al., 2013). Finally, the modal value for fixation time of EDAR V370A has been estimated (using haplotype data from 23 individuals of Chinese descent) as 10,740 years BP (Bryk et al., 2008). These estimates for origination and fixation of EDAR V370A within East Asia are recent relative to the age of our species, and are also suggestive of powerful selective forces at play over a short time interval.

Because scalp hair density is increased by EDAR V370A, various authors have suggested that thermoregulatory and water balance would be influenced by this morphological change, particularly in the cooler and drier climates of the Upper Paleolithic (see Yuan et al., 2004; Chang et al., 2009). An alternative hypothesis links increased eccrine (sweat) gland density to greater evaporative heat loss in a humid monsoonal climate (Kamberov, et al., 2013). Mammary duct density also increases in the presence of EDAR V370A, raising the possibility of enhanced maternal milk delivery and associated fitness benefits (Hlusko et al., 2018). Concomitant changes in dentition may thus have derived pleiotropically from selection on other traits.

However, Sinodonty by definition refers to tooth anatomy, which broadly reflects diet in mammals (Ungar, 2010; Pineda-Munoz et al., 2017). It is therefore parsimonious to consider dietary shifts concurrent with the rise of EDAR V370A and associated elements of Sinodonty that may have been the target of natural selection. In particular, the timeline for fixation of this allele, along with its inferred geographical region of origin, correspond well to archaeological data that indicate foraging of wild rice and millet in China, along with their subsequent domestication. The origins of prominent features of Sinodonty, in other words, correlate temporally with a major dietary shift associated with the emergence of cultivated crops in East Asia. I hypothesize that this specialized human dentition, along with other related phenotypic effects of EDAR V370A, were advantageous for the mastication and subsequent digestion of sympatric wild grains, and thus yielded energetic advantage during the extended process of crop domestication.
Timeline for rice and millet domestication in China Domesticated rice in East Asia refers to a single subspecies (Oryza rufipogon ssp. japonica) derived from a wild ancestor, whereas millet refers to two species domesticated from different grass genera (broomcorn millet: Panicum miliaceum; foxtail millet: Setaria italica). Phylogenetic reconstruction places rice domestication in China at $\sim 13,500-8200$ BP (Molina et al., 2011), a range congruent with corroborative archeological evidence (see Liu et al., 2007; Gross \& Zhao, 2014). Similarly, archeological finds are consistent with the domestication and cultivation of millet nearly 10,000 years ago (Lu et al., 2009; Yang et al., 2012; Bestel et al., 2014).

Foraging on wild grains would have necessarily preceded their domestication. For example, processing with grinding stones of wild grass seeds (including possibly ancestral millets) occurred as early as $\sim 24,000$ years BP (see Liu et al., 2013; Liu et al. 2018). The oldest known sites for pottery in China date to $\sim 20,000-10,000$ years BP, possibly marking the emergence of agriculture (see Wang \& Sebillaud, 2019). Starchy foods more generally became increasingly prevalent through the Upper Paleolithic in China, as suggested by increased usage of nuts, beans, and tubers (see Liu et al., 2013). Archeological records cannot capture in detail the spectrum of foraging and cultivation behaviors carried out over millennia, and across a geographical mosiac, during the process of crop domestication (see Fuller et al., 2014; Larson et al., 2014). Nonetheless, the overlap between estimated timelines for the origin and fixation of EDAR V370A, and for the domestication of rice and millet, is substantial (Figure 1).

\section{Functional consequences of Sinodonty}

Shoveled incisors and related features of Sinodonty may influence chewing dynamics and masticatory efficiency. It has long been suggested that shoveling increases tooth strength and resistance to bending (see Hrdlička, 1921; Dahlberg, 1963). Specific effects of incisor shoveling and changes in premolar and molar root numbers are unknown for mastication, which is associated with diverse features of jaw kinematics (see Ross et al., 2012). Also relevant is the substantial reduction in mandibular length associated with expression of the EDAR allele (by 5-10\% in mice; see Adhikari et al., 2016). In human agriculturalists, mandible dimensions are reduced relative to non-agricultural populations, consistent with relaxation of masticatory demand (see von Cramon-Taubadel, 2011; Noback \& 

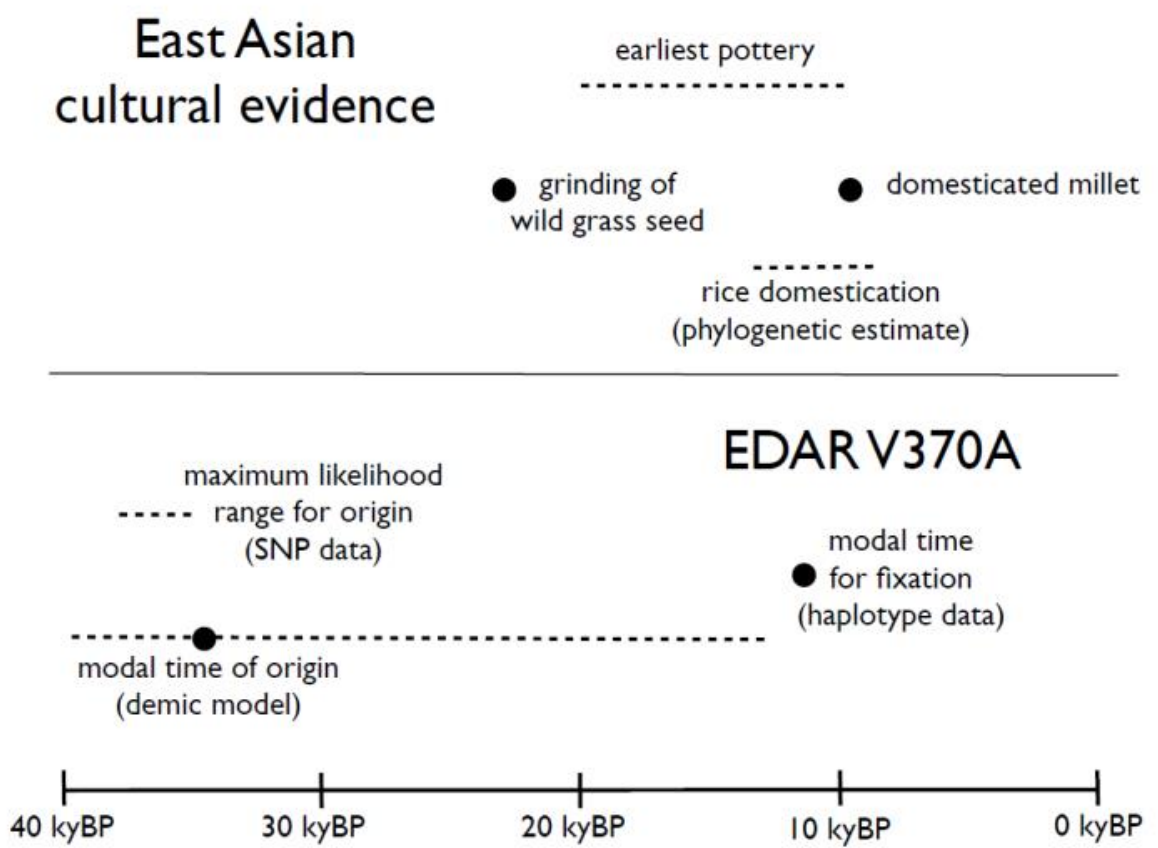

Figure 1. Timelines for estimated origin and fixation of EDAR V370A, and for relevant archaeological data and estimates of crop domestication. Dashed lines indicate approximate temporal ranges; see text for details and relevant citations.

Harvati, 2015; Katz et al., 2017). Paleontological data are not available to document the tempo of mandibular reduction across the rice and millet domestication sequence in East Asia, but a causal link with EDAR V370A cannot be excluded.

Interestingly, another consequence of enhanced EDAR expression in mice is to increase branching of adult salivary glands (by $\sim 25 \%$; Chang et al., 2009), which may in turn increase rates of saliva production and thereby facilitate starch digestion in the mouth (Valdez \& Fox, 1991). This mechanism would provide a direct linkage between anatomical changes associated with EDAR V370A expression in humans, and advantageous physiological outcome as starchy crops were domesticated. An analogous argument was advanced by Hlusko et al. (2018) relative to increases in mammary duct density and lactation; such effects on gland density could moreover be complementary in some contexts (e.g., greater energy uptake would enable increased milk production), and would pertain independently of any specific climatic conditions. Pleiotropic changes in teeth, mandibular bone, and salivary gland density resulting from EDAR V370A can therefore influence human nutritional physiology in diverse ways.

\section{Discussion and Conclusions}

Various alleles alternative to EDAR V370A may contribute to tooth shoveling and other features characteristic of Sinodonty, and do not necessarily correspond to specific dietary adaptations. Prominent incisor shoveling in Neanderthals, for example, well precedes the origin of EDAR V370A, and does not associate with increased masticatory stresses (Clement et al., 2012). Similarly, a 3-rooted lower second molar has been described from a Denisovan mandible from western China, dated at $\sim 160,000$ BP (Bailey et al., 2019), although identification of this tooth has been challenged (see Scott et al., 2020; Bailey et al., 2020). The age of this specimen nonetheless well precedes the 38,000-35,000 BP estimated origination time for EDAR V370A (see Kamberov et al., 2013), and its features presumably derive from different genetic origins. Incisor shoveling in Native Americans likely derives genetically from their Eurasian source populations in northeastern Siberia (see Flegontov et al., 2019; Mathieson, 2020), but the oldest known human dentition from this latter region $(\sim 31,000 \mathrm{BP})$ is unfortunately incomplete with unknown occurrence of Sinodonty (see Sikora et al., 2019). The increased incidence of shoveling in Down syndrome 
(see Cohen et al., 1970) is not yet characterized at the allelic level. Finally, an additional EDAR variant is found in south China and southeast Asia, but has not apparently been the target of positive selection (Riddell et al., 2020).

A pressing empirical need to evaluate any functional hypothesis relating to Sinodonty and to effects of EDAR V370A is to obtain a quantitative assessment of tooth and mandibular variation through time in East Asia. Changes in dentition and mandibular dimensions across the Paleolithic in China are not currently available, although there was a substantial reduction in mandibular dimensions from the Neolithic through the Bronze Age (Li et al., 2012). Incisor shoveling incidence in western European populations (which is low relative to that found in East Asia) has declined since the Neolithic (Brabant, 1971), a trend which may derive from genetic drift. Quantitative measurements of tooth morphology (e.g., Carayon et al., 2018) would enable better characterization of the shoveling phenotype and associated variation through time and among human populations, along with finite-element modeling of tooth bending mechanics. Similarly, consequences of changes in mandibular geometry can be inferred from mechanical modeling, although functional outcomes can be complex and not necessarily predictable from linear data (Sella-Tunis et al., 2018), to which end three-dimensional structural modelling using finite-element analysis would be appropriate (see Morales-García et al., 2019).

Multiple hypotheses pertain to the possible selective advantages of EDAR V370A, and none of these are mutually exclusive. Recognition of the temporal correlation between allele age and the timelines for wild grain consumption and domestication in East Asia, however, provides a linkage between diet and nutritional gain during the transition to agriculture. Worldwide, this transition has been associated with diverse changes in human behavior and morphological features, and is suggestive of powerful selective forces at play. For example, an allele for a highly active form of alcohol dehydrogenase originated in central China in parallel with rice domestication, prompting speculation as to increased dietary exposure to ethanol derived from carbohydrate fermentation (Peng et al., 2010). The pleiotropic effects of EDAR V370A are multifaceted, and unifactorial explanations for associated selective forces are likely to be incomplete. Nonetheless, chronic energetic benefits concurrent with grain domestication in East Asia have not previously been envisioned for this allele, and may have been of considerable advantage.

\section{Acknowledgments}

I thank Professor Li Liu and two anonymous reviewers for helpful comments on the manuscript.

\section{REFERENCES}

Adhikari, K. et al. (2016). A genome-wide association scan implicates DCHS2, RUNX2, GLI3, $P A X 1$ and EDAR in human facial variation. $\mathrm{Na}$ ture Communications, 7, 11616.

Bailey, S.E., Hublin, J.-J., \& Antón, S.C. (2019). Rare dental trait provides morphological evidence of archaic introgression in Asian fossil record. Proceedings of the National Academy of Sciences USA, 116, 14806-14807.

Bailey, S.E., Kupczik, K., Hublin, J.-J., \& Antón, S.C. (2020). A closer look at the 3-rooted lower second molar of an archaic human from Xiahe. Proceedings of the National Academy of Sciences USA, 117, 39-40.

Bestel, S., Crawford, G.W., Liu, L., Shi, J., Song, Y., \& Chen, X. (2014). The evolution of millet domestication, Middle Yellow River Region, North China: Evidence from charred seeds at the late Upper Paleolithic Shizitan Locality 9 site. The Holocene, 24, 261-265.

Blanco, R., \& Chakraborty, R. (1976). The genetics of shovel shape in maxillary central incisors in man. American Journal of Physical Anthropology, 44, 233-236.

Brabant, H.E. (1971). The human dentition during the Megalithic era. In A.A. Dahlberg (Ed.): Dental Morphology and Evolution (pp. 283-297). Chicago: University of Chicago Press.

Bryk, J., Hardouin, E., Pugach, I., Hughes, D., Strotmann, R., Stoneking, M., \& Myles, S. (2008). Positive selection in East Asians for an EDAR allele that enhances NF-kB activation. PLoS ONE 3, e2209.

Carayon, D. et al. (2018). A geometric morphometric approach to the study of variation of shovelshaped incisors. American Journal of Physical Anthropology, 168, 229-241.

Chang, S.H., Jobling, S., Brennan, K., \& Headon, D.J. (2009). Enhanced Edar signalling has pleiotropic effects on craniofacial and cutaneous glands. PLoS ONE, 4, e7591.

Clement, A.F., Hillson, S.W., \& Aiello, L.C. (2012). Tooth wear, Neanderthal facial morphology and the anterior dental loading hypothesis. Journal of Human Evolution, 62, 367-376.

Cohen, M.M., Blitzer, F.J., Arvystas, M.G., and 
Bonneau, R.H. (1970). Abnormalities of the permanent dentition in trisomy G. Journal of Dental Research, 49, 1386-1393.

Dahlberg, A.A. (1963). Dental evolution and culture. Human Biology, 35, 237-249.

Flegontov, P. et al. (2019). Palaeo-Eskimo genetic ancestry and the peopling of Chukokta and North America. Nature, 570, 236-240.

Fujimoto, A., Ohashi, J., Nishida, N., Miyagawa, T., Morishita, Y., Tsunoda, T., Kimura, R., \& Tokunaga, K. (2008). A replication study confirmed the EDAR gene to be a major contributor to population differentiation regarding head hair thickness in Asia. Human Genetics, 124, 179-185.

Fuller, D.Q. et al. (2014). Convergent evolution and parallelism in plant domestication revealed by an expanding archeological record. Proceedings of the National Academy of Sciences USA, 111, 6147 $-6152$.

Gross, B.L., \& Zhao, Z. (2014). Archaeological and genetic insights into the origins of domesticated rice. Proceedings of the National Academy of Sciences USA, 111, 6190-6197.

Hanihara, K., Masuda, T., \& Tanaka, T. (1974). Family studies of the shovel trait in the maxillary central incisor. Journal of the Anthropological Society of Nippon, 83, 107-112.

Hlusko, L.J. et al. (2018). Environmental selection during the last ice age on the mother-to-infant transmission of vitamin D and fatty acids through breast milk. Proceedings of the National Academy of Sciences USA, 115, E4426-E4432.

Hrdlička, A. (1920). Shovel-shaped teeth. American Journal of Physical Anthropology, 3, 429-465.

Hrdlička, A. (1921). Further studies of tooth morphology. American Journal of Physical Anthropolo$g y, 4,141-176$.

Kamberov, Y.G. et al. (2013). Modeling recent human evolution in mice by expression of a selected EDAR variant. Cell, 152, 691-702.

Katz, D.C., Grote, M.N., \& Weaver, T.D. (2017). Changes in human skull morphology across the agricultural transition are consistent with softer diets in preindustrial farming groups. Proceedings of the National Academy of Sciences USA, 114, 9050-9055.

Kimura, R., Yamaguchi, T., Takeda, Y., Kondo, O., Toma, T., Haneji, K., Hanihara, T., Matsukura, H., kawamura, S., Maki, K., et al. (2009). A common variation in EDAR is a genetic determinant of shovel-shaped incisors. American Journal of Human Genetics, 85, 528-535.

Larson, G. et al. (2014). Current perspectives and the future of domestication studies. Proceedings of the National Academy of Sciences USA, 111, 6139 $-6146$.

Li, H., Zhuan, Q., \& Zhu, H. (2012). The size variation and related implications of mandibles in northern China in the past 7000 years. Chinese Science Bulletin, 57, 387-394.

Liu, L., Lee, G.-A., Jiang, L., \& Zhang, J. (2007). Evidence for the early beginning (c. $9000 \mathrm{cal}$. BP) of rice domestication in China: a response. The Holocene, 17, 1059-1068.

Liu, L. et al. (2018). Harvesting and processing wild cereals in the Upper Palaeolithic Yellow River Valley, China. Antiquity, 92, 603-619.

Liu, L., Bestel, S., Shi, J., Song, Y., \& Chen, X. (2013). Paleolithic human exploitation of plant foods during the last glacial maximum in North China. Proceedings of the National Academy of Sciences USA, 110, 5380-5385.

$\mathrm{Lu}, \mathrm{H}$. et al. (2009). Earliest domestication of common millet (Panicum miliaceum) in East Asia extended to 10,000 years ago. Proceedings of the National Academy of Sciences USA, 106, 73677372.

Mathieson, I. (2020). Limited evidence for selection at the FADS locus in Native American populations. Molecular Biology and Evolution, 37, 20292033.

Mizoguchi, Y. (1985). Shovelling: A Statistical Analysis of its Morphology. Tokyo: University of Tokyo Press.

Molina, J. et al. (2011). Molecular evidence for a single evolutionary origin of domesticated rice. Proceedings of the National Academy of Sciences USA, 108, 8351-8356.

Noback, M.L., \& Harvati, K. (2015). The contribution of subsistence to global human cranial variation. Journal of Human Evolution, 80, 34-50.

Park, J.-H. et al. (2012). Effects of an Asian-specific non-synonymous EDAR variant on multiple dental traits. Journal of Human Genetics, 57, 508514.

Peng, Y. et al. (2010). The ADH1B Arg47His polymorphism in East Asian populations and expansion of rice domestication in history. BMC Evolutionary Biology, 10, 15.

Pineda-Munoz, S., Lazagabaster, I.A., Alroy, J., \& Evans, A.R. (2017). Inferring diet from dental morphology in terrestrial mammals. Methods in Ecology and Evolution, 8, 481-491.

Riddell, J., Mallick, C.B., Jacobs, G.S., Schoenebeck, J.J, \& Headon, D.J. (2020). Characterisation of a second gain of function EDAR variant, encoding EDAR380R, in East Asia. European Journal of 
Human Genetics, doi.org/10.1038/s41431-0200660-6.

Ross, C.F., Iriarte-Diaz, J., \& Nunn, C.L. (2012). Innovative approaches to the relationship between diet and mandibular morphology in primates. International Journal of Primatology, 33, 632 $-660$.

Sabeti, P.C. et al. (2007). Genome-wide detection and characterization of positive selection in human populations. Nature, 449, 913-919.

Scott, G.R. \& Turner, C.G. (1988). Dental anthropology. Annual Review of Anthropology, 17, 99-126.

Scott, G.R., Irish, J.D., \& Martinón-Torres, M. (2020). A more comprehensive view of the Denisovan 3-rooted lower second molar from Xiahe. Proceedings of the National Academy of Sciences USA, 117, 37-38.

Scott, G.R., Turner, C.G., Townsend, G.C., \& Martinón-Torres, M. (2018). The Anthropology of Modern Human Teeth: Dental Morphology and its Variation in Recent and Fossil Homo sapiens. Cambridge; New York, NY: Cambridge University Press.

Sella-Tunis, T., Pokhojaev, A., Sarig, R., O'Higgins, P., \& May, H. (2018). Human mandibular shape is associated with masticatory muscle force. Scientific Reports, 8, 6042.

Stojanowski, C.M., Johnson, K.M., \& Duncan, W.N. (2013). Sinodonty and beyond: hemispheric, regional, and intracemetery approaches to studying dental morphological variation in the New World. In G.R. Scott and J.D. Irish (Eds.), Anthropological Perspectives on Tooth Morphology: Genetics, Evolution, Variation (pp. 408-452). Cambridge: Cambridge University Press.

Turner, C.G. (1971). Three-rooted mandibular first permanent molars and the question of American Indian origins. American Journal of Physical Anthropology, 34, 229-241.

Turner, C.G. (1976). Dental evidence on the origins of the Ainu and Japanese. Science, 193, 911- 913.

Turner, C.G. (1986). Dentochronological separation estimates for Pacific rim populations. Science, 232, 1140-1142.

Turner, C.G. (1990). Major features of Sundadonty and Sinodonty, including suggestions about East Asian microevolution, population history, and late Pleistocene relationships with Australian Aboriginals. American Journal of Physical Anthropology, 82, 295-317.

Turner, C.G., \& Bird, J. (1981). Dentition of Chilean paleo-Indians and peopling of the Americas. Science, 212, 1053-1055
Ungar, P.S. (2010). Mammal teeth. Baltimore: Johns Hopkins University Press.

Valdez, I.H., \& Fox, PC. (1991). Interactions of the salivary and gastrointestinal systems. I. The role of saliva in digestion. Digestive Diseases, 9, 125132.

von Cramon-Taubadel, N. (2011). Global mandibular variation reflects differences in agricultural and hunter-gatherer subsistence strategies. Proceedings of the National Academy of Sciences USA, 108, 19546-19551.

Wang, L., \& Sebillaud, P. (2019). The emergence of early pottery in East Asia: new discoveries and perspectives. Journal of World Prehistory, 32, 73110.

Yang, X., Wan, Z., Perry, L., Lu, H., Wang, Q., Zhao, C., Li, J., Xie, F., Yu, J., Cui, T., Wang, T., Li, M., Ge, Q. (2012). Early millet use in northern China. Proceedings of the National Academy of Sciences USA, 109, 3726-3730. 